\title{
PLANTAS HOSPEDEIRAS DAS ESPÉCIES DE AGRIAS DOUBLEDAY (LEPIDOPTERA, NYMPHALIDAE, CHARAXINAE) $^{1}$
}

\author{
Mirna M. Casagrande ${ }^{2}$ \\ Olaf H.H. Mielke ${ }^{2}$
}

As borboletas do gênero Agrias Doubleday, 1844 são as mais cobiçadas pelos colecionadores, causando, eventualmente, pressões negativas sobre as suas populações. Para minimizar esta possibilidade, assim como elucidar a biologia das várias espécies, seria conveniente obtê-las através de criações em cativeiro, o que não é difícil. As fêmeas, das espécies já criadas (ver referências abaixo), ovipositam com facilidade em suas plantas alimentícias. Consequentemente, é necessário, em primeiro lugar, conhecer as plantas hospedeiras das lagartas. Como só três plantas hospedeiras de duas das cinco espécies de Agrias eram conhecidas (FURTADO 1984; CASAGRANDE \& MiELKE 1985; KESSELRING 1989), relaciona-se mais cinco plantas hospedeiras das mesmas espécies de Agrias e repete-se os dados das três outras já conhecidas.

\section{Agrias claudina claudianus Staudinger, [1885]}

1. Quiina glaziovii Engler (Quiinaceae) - Joinville, Santa Catarina. Nome popular: carobrano (CASAGRANDE \& MiELKE 1985).

2. Ouratea parviflora (DC.) Baill. (Ochnaceae) -Joinville, Santa Catarina. Nome popular: pau de bugre.

3. Hirtella hebeclada Moric. ex A.P. de Candolle (Chrysobalanaceae) - Joinville, Santa Catarina. Nome popular: guamirim vidro.

4. Vantanea compacta (Schnitzl.) Cuatr. ssp. compacta (Humeriaceae) - Joinville, Santa Catarina. Nome popular: guarapari ou guaraparin.

\section{Agrias claudina godmani Fruhstorfer, 1895}

1. Hirtella gracilipes (Hook. f.) (Chrysobalanaceae) - Diamantino, Mato Grosso.

\section{Agrias amydon ferdinandi Fruhstorfer, 1895}

1. Erythroxylum anguifugum Mart. (Erythroxylaceae) - Diamantino, Mato Grosso (FURTADO 1984).

2. Erythroxylum simonis Plowman (Erythroxylaceae) - Tiuma, Pernambuco (KESSELRING 1989).

3. Erythroxylum barbatum O.E. Schulz (Erythroxylaceae) - Tiuma, Pernambuco.

1) Contribuição número 1038 do Departamento de Zoologia, Universidade Federal do Paraná.

2) Departamento de Zoologia, Universidade Federal do Paraná. Caixa Postal 19020, 81531-990 Curitiba, Paraná, Brasil. Bolsista do CNPq. 
AGRADECIMENTOS. Agradecemos aos amigos e incansáveis amantes das borboletas brasileiras Srs. Herbert Miers (Joinville, Santa Catarina), Eurides Furtado (Diamantino, Mato Grosso) e Jorge Kesselring (João Pessoa, Paraiba) pelas informações das plantas hospedeiras e ao Dr. Gert Hatschbach (Museu Botânico Municipal, Curitiba, Paraná) pela identificação das mesmas.

\section{REFERÊNCIAS BIBLIOGRÁFICAS}

Casagrande, M.M. \& O.H.H. MielKe. 1985. Estágios imaturos de Agrias claudina claudianus Staudinger (Lepidoptera, Nymphalidae, Charaxinae). Revta bras. Ent. 29: 139-142.

FuRTADO, E. 1984. Contribuição ao conhecimento dos lepidópteros brasileiros - I. Biologia de Agrias amydon ferdinandi Fruhstorfer (Nymphalidae, Charaxinae). Revta bras. Ent. 28: 280-294.

Kesselring, J. 1989. Agrias, a rainha das borboletas. Ciência Hoje, Rio de Janeiro, 10 (60): 40-48.

Recebido em 10.I.1996; aceito em 20.X.1997. 